Printed in Nigeria

\title{
Association between blood pressure and some other cardiovascular disease risk factors in a lean black population
}

\section{Chukwunonso E.C.C. EJIKE, ${ }^{* 1,2}$ Chidiebere E. UGWU ${ }^{2,3}$ and Lawrence U.S. EZEANYIKA ${ }^{2,3}$}

\author{
${ }^{1}$ Department of Biochemistry, Michael Okpara University of Agriculture, Umudike, PMB \\ 7267, Umuahia, Nigeria \\ ${ }^{2}$ Department of Biochemistry, University of Nigeria, Nsukka, Nigeria \\ ${ }^{3}$ Department of Biochemistry, Kogi State University, Anyigba, Nigeria
}

Received November 20, 2009

MS/No BKM/2009/064, (c) 2009 Nigerian Society for Experimental Biology. All rights reserved.

\begin{abstract}
Blood pressures, serum total cholesterol levels, blood glucose levels, anthropometric parameters and ages of five hundred and thirty eight adult Nigerians, living in two localities were measured using standard protocol. The mean age of the subjects was $50.5 \pm 10.8$ years while their mean body mass index (BMI) was $24.9 \pm 5.0 \mathrm{~kg} / \mathrm{m}^{2}$. Hypertensive subjects who had desirable serum total cholesterol levels had lower systolic blood pressure (SBP) $(152.33 \pm 19.55 \mathrm{mmHg}$, for males, and $145.60 \pm 18.64$ $\mathrm{mmHg}$, for females) compared to those who had undesirable serum total cholesterol levels (174.02 \pm $24.93 \mathrm{mmHg}$, for males, and $177.65 \pm 31.11 \mathrm{mmHg}$, for females). For normotensive subjects, serum total cholesterol status did not significantly affect SBP. SBP in the hypertensive subjects was highest in the overweight group $(159.17 \pm 25.31 \mathrm{mmHg})$ and lowest in the obese group $(150.69 \pm 20.14$ $\mathrm{mmHg}$ ). In normotensive subjects, SBP did not change markedly between the BMI groups. Data on the effects of age and blood glucose levels are presented. Risk factors for hypertension may not affect individuals with and without the disorder linearly. The underlying mechanistic processes that link changes in these risk factors to their physiological consequences for blood pressure elevation and regulation deserve more attention
\end{abstract}

Keywords: blood glucose, blood pressure, body mass index, serum total cholesterol

\footnotetext{
*To whom correspondence should be addressed. E-mail: nonsoejikeecc@yahoo.com, ejike.nonso@mouau.edu.ng Tel: +2348036066777
} 


\section{INTRODUCTION}

The prevalence of cardiovascular diseases is increasing steeply in the developing world and may be related to the rapidly aging population, changing lifestyles and nutrition transition in those regions of the world ${ }^{1}$. Blood pressure (BP) is generally accepted to have a role in accelerating atherosclerosis of the blood vessels and thereby influencing cardiovascular disease $^{2}$. Prospective cohort studies have demonstrated a strong association between blood pressure and stroke, ischaemic heart disease, renal disease and other cardiovascular diseases $^{3-7}$. Globally high BP is estimated to cause 7.1 million deaths, about $13 \%$ of the total $^{8}$. However, high blood pressure is still largely ignored as a public health problem in many developing countries ${ }^{9}$, despite the fact that such countries are increasingly faced with the double burden of hypertension and other cardiovascular diseases, along with infection and malnutrition ${ }^{8,10}$. Since developing countries cannot afford the high cost of treating hypertension and its sequelea in large portions of their population, appropriate preventive measures should be put in place to control risk factor levels in the general population and in individuals at risk $^{11}$. Correlations between body mass index (BMI) and BP have been shown in Caucasian ${ }^{12,13}$, African ${ }^{14,15}$ and Asian 16,17 populations. Elevated BP has also been linked to serum total cholesterol levels and blood glucose levels ${ }^{18-20}$. In fact, a lot has documented on the correlates of blood pressure and its co-morbid conditions. However, whether the risk factors - age, gender, BMI, serum total cholesterol concentration and blood glucose concentration - affect hypertensive individuals and normotensive individuals alike, has not been given appropriate attention, especially in lean populations of Africa. This study investigates our hypothesis that these risk factors affect individuals with and without hypertension disproportionately.

\section{SUBJECTS AND METHODS}

Nigerian men and women aged 30-74 years were studied. The participants were from Anyigba (Kogi state) and Nsukka (Enugu state) - both states are geographically neighbours with Kogi bordering Enugu to the North Anyigba and Nsukka are host towns to the Kogi State University and the University of Nigeria, respectively. The study was advertised locally in the two towns and those who indicated interest and gave an informed consent were allowed to participate in the study.

Participants had their blood pressure measured using a digital blood pressure monitor (Omron model HEM-741 CINT, Omron Healthcare Inc., Illinois, USA) between 8am and 10am. Three separate readings were taken (after a two minutes interval each) per individual (in a sitting position after an initial ten minutes rest) per day, and the average of the second and third readings recorded. Subjects who had a mean systolic blood pressure (SBP) $\geq$ $140 \mathrm{mmHg}$ and/or a mean diastolic blood pressure (DBP) $\geq 90 \mathrm{mmHg}$ were re-evaluated on a different day, and those who consistently had $\mathrm{SBP} / \mathrm{DBP} \geq 140 / 90 \mathrm{mmHg}$, or who reported using antihypertensive medication were classified as hypertensives (tests) ${ }^{21}$. While those with a mean SBP and DBP $<140$ and $<90$ respectively were classified as normotensives (controls).

Measurement of weight and height were taken, with subjects dressed in light clothing and the BMI calculated [weight $(\mathrm{kg}) /$ height $(\mathrm{m})^{2}$ ]. Subjects were grouped as thin $(\mathrm{BMI}<18,5)$, normal $(18.5 \leq \mathrm{BMI} \leq 24.9)$, overweight $(25 \leq$ $\mathrm{BMI} \leq 29.9)$ and obese $(\mathrm{BMI} \geq 30)^{22,23}$.

Fasting blood samples $(2 \mathrm{ml})$ were drawn from each participant using a $4 \mathrm{ml}$ syringe, and transferred into clean sample containers. A drop of whole blood was removed from each container immediately and used for the measurement of whole blood glucose, using a glucometre (Accu-Chek Advantage, Roche Diagnostics, Mannheim, Germany). The glucometre was calibrated using standard test strips and solutions supplied by the manufacturer. Blood samples were allowed to stand at ambient temperature until clotting took place. The serum was separated completely by centrifugation for 5 minutes. From the serum, the total cholesterol concentration was measured by the method of Allain $e t a l^{24}$.

Subjects were grouped as having desirable serum total cholesterol if they had values $<5.17 \mathrm{mmol} / \mathrm{L}$, and as having undesirable 
serum total cholesterol if they had values $\geq 5.17 \mathrm{mmol} / \mathrm{L}^{25}$. Subjects who had a fasting blood glucose level of $>115 \mathrm{mg} / \mathrm{dL}$ were classified as having high blood glucose levels while those who had blood glucose levels $\leq 115 \mathrm{mg} / \mathrm{dL}$ were classified as having normal blood glucose levels ${ }^{25}$. None of the participants presented with hypoglyceamia.

Age at last birthday as reported by each participant, was recorded. From that, they were grouped in age-ranges of ten years each (except for the last age-range) starting from 30-39years.

The study protocol was prepared in accordance with the Helsinki Declaration and was approved by the Board of the Department of Biochemistry, Kogi State University, Anyigba.

\section{Statistical analysis}

Descriptive statistics was done to get the characteristics of the subjects, represented as means \pm standard deviations. Differences between means were checked for significance using the one way ANOVA and multiple comparison tests. The Pearson's product moment correlation was used to assess correlations between variables. Multivariate linear regression models were used to examine the association between the variables and both SBP and DBP. Differences between means, and associations/correlations were significant at $\mathrm{p}<0.05$. Analyses were performed using SPSS for windows version 11.0 (SPSS Inc, Chicago, IL).

\section{RESULTS}

A total of five hundred and forty two (542) subjects participated in the study. The characteristics of the studied population are shown in Table 1.

SBP correlated positively with age, DBP, serum total cholesterol concentration and blood glucose concentration. DBP apart from correlating with SBP also correlated with the same parameters as SBP, as shown in Table 2.

The linear regression model $\left(\mathrm{R}^{2}=0.55\right)$ however showed that only DBP and serum total cholesterol concentration contributed (positively) to the increase in SBP; while SBP, age and serum total cholesterol concentration contributed positively) to the increase in DBP (Table 2).

Table 1: Characteristics of the subjects

\begin{tabular}{lccccc}
\hline & All Subjects & \multicolumn{2}{c}{ Male } & \multicolumn{2}{c}{ Female } \\
\cline { 3 - 6 } Parameter & $(\mathrm{n}=542)$ & Test $(\mathrm{n}=200)$ & Control $(\mathrm{n}=68)$ & Test $(\mathrm{n}=180)$ & Control $(\mathrm{n}=94)$ \\
\hline Age $($ Yrs $)$ & $50.5 \pm 10.8$ & $52.9 \pm 11.6$ & $50.4 \pm 12.3$ & $50.1 \pm 8.6$ & $46.2 \pm 10.4$ \\
SBP $(\mathrm{mmHg})$ & $144.8 \pm 27.2$ & $156.8 \pm 22.5$ & $116.8 \pm 8.9$ & $154.3 \pm 26.8$ & $120.2 \pm 10.6$ \\
DBP $(\mathrm{mmHg})$ & $88.1 \pm 14.1$ & $93.7 \pm 13.3$ & $74.2 \pm 8.3$ & $93.6 \pm 10.7$ & $75.1 \pm 8.1$ \\
BMI $\left(\mathrm{kg} / \mathrm{m}^{2}\right)$ & $24.9 \pm 5.0$ & $24.9 \pm 4.3$ & $24.6 \pm 8.7$ & $25.0 \pm 5.0$ & $25.0 \pm 3.6$ \\
Cholesterol $(\mathrm{mmol} / \mathrm{L})$ & $3.9 \pm 1.4$ & $4.1 \pm 1.3$ & $3.0 \pm 1.2$ & $4.5 \pm 1.3$ & $3.2 \pm 1.3$ \\
Glucose $(\mathrm{mg} / \mathrm{dL})$ & $107.8 \pm 53.8$ & $106.1 \pm 49.0$ & $95.7 \pm 41.9$ & $118.7 \pm 65.1$ & $100.0 \pm 43.0$ \\
\hline
\end{tabular}

Table 2: Associations and correlations between variables and SBP and DBP

\begin{tabular}{|c|c|c|c|c|c|c|c|c|c|c|}
\hline \multirow[b]{3}{*}{ Variable } & \multicolumn{4}{|c|}{ Correlation } & \multicolumn{6}{|c|}{ Regression } \\
\hline & \multicolumn{2}{|c|}{ SBP } & \multicolumn{2}{|c|}{ DBP } & \multicolumn{3}{|c|}{ SBP } & \multicolumn{3}{|c|}{$\overline{D B P}$} \\
\hline & $\mathrm{r}$ & $\mathrm{p}$ & $\mathrm{r}$ & $p$ & $\beta$ & SE & $\mathrm{p}$ & $\beta$ & SE & $\mathrm{p}$ \\
\hline Age & 0.153 & 0.000 & 0.186 & 0.000 & -0.015 & 0.076 & 0.631 & 0.065 & 0.041 & 0.031 \\
\hline BMI & 0.039 & 0.367 & 0.064 & 0.137 & -0.002 & 0.160 & 0.941 & 0.124 & 0.086 & 0.001 \\
\hline Cholesterol & 0.516 & 0.000 & 0.463 & 0.000 & 0.244 & 0.673 & 0.000 & 0.008 & 0.373 & 0.811 \\
\hline Glucose & 0.195 & 0.000 & 0.169 & 0.000 & 0.034 & 0.015 & 0.267 & 0.629 & 0.008 & 0.000 \\
\hline Sex & -0.072 & 0.097 & -0.042 & 0.252 & -0.070 & 1.625 & 0.019 & -0.007 & 0.875 & 0.089 \\
\hline SBP & - & - & 0.706 & 0.000 & - & - & - & 0.587 & 0.018 & 0.000 \\
\hline DBP & 0.706 & 0.000 & - & - & 0.629 & 0.664 & 0.00 & - & - & - \\
\hline
\end{tabular}


Grouping the subjects into test and control groups and according to their age-ranges showed that SBP increased with age in the hypertensive group (from $144.9 \pm 15.1 \mathrm{mmHg}$ for those aged 30-39 years, to $162.7 \pm 22.9$ $\mathrm{mmHg}$ for those aged 70-74 years) (Figure 1). In the test group, the differences in the mean
SBP values of those aged 30-39 years compared to the others were significant $(\mathrm{p}<0.05)$.

For the control group, the differences in the mean SBP values of any age-range compared to that of any other age-range was not significant $(\mathrm{p}>0.05)$.

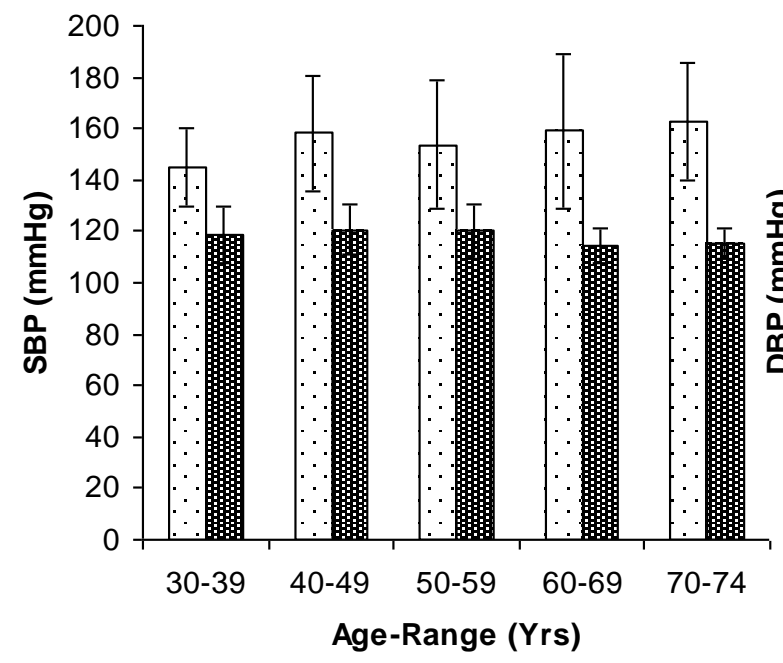

$\square$ Test 闻 Control

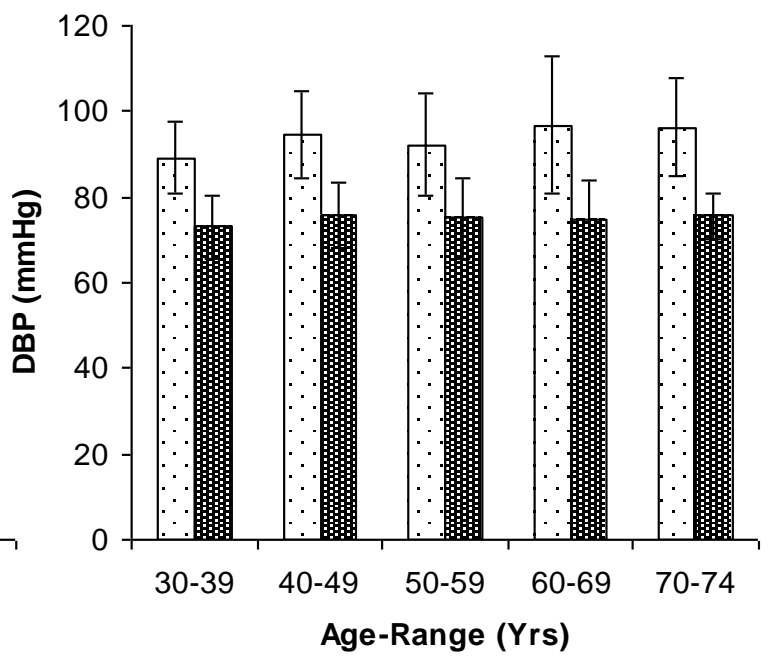

$\square$ Test 国 Control

Figure 1: Systolic and Diastolic blood pressures of subjects distributed according to their age ranges.

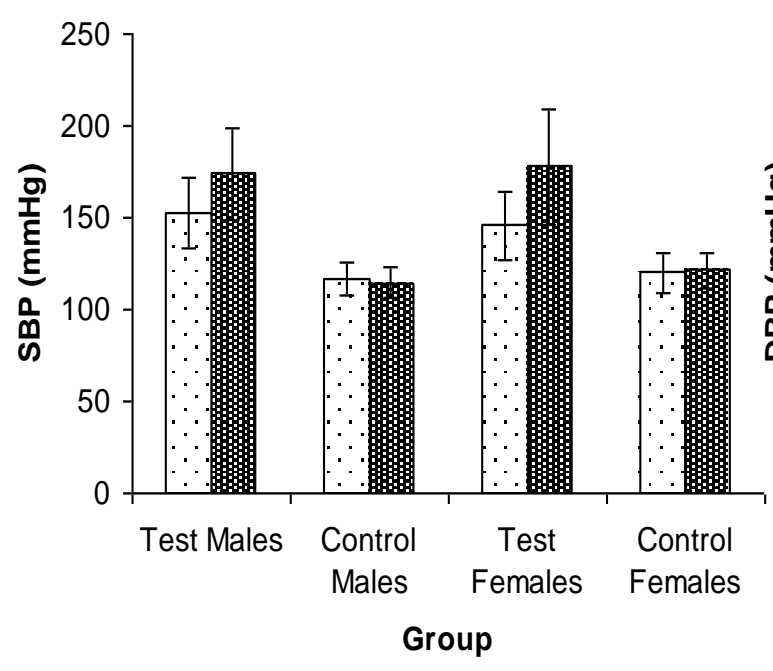

$\square$ Desirable 图 Undesirable

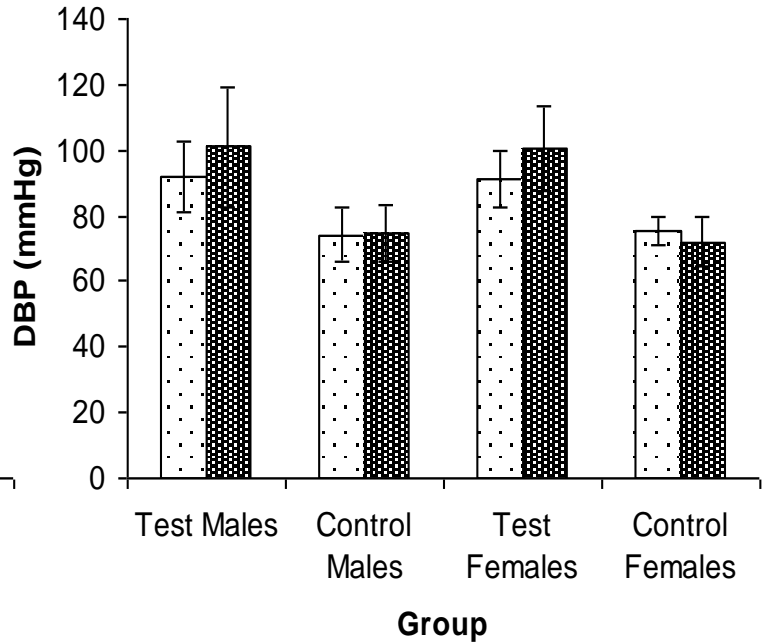

$\square$ Desirable 目 Undesirable

Figure 2: Systolic and Diastolic blood pressures of subjects distributed according to their serum total cholesterol concentrations.

DBP like SBP increased with age in the hypertensive group (from $89.2 \pm 8.4 \mathrm{mmHg}$ for those aged $30-39$ years to $96.3 \pm 11.4$ $\mathrm{mmHg}$ for those aged 70-74 years. Comparing between the mean DBP values for the test group showed that the differences between the values for those aged 30-39 years and any other group (excluding 50-59 years) were significant $(\mathrm{p}<0.05)$. In the control group, the differences in the mean DBP values for any age-range compared to any other age-range were not significant $(\mathrm{p}>0.05)$. Grouping the subjects along serum total cholesterol lines (for both sexes) in the hypertensive and normotensive subjects showed that in both male and female hypertensive subjects, those who had undesirable serum total cholesterol levels had higher SBP (Figure 2). For 
normotensive males and females, SBP did not change appreciably with change in serum total cholesterol status. DBP in both the hypertensive and normotensive subjects followed the trend described for SBP.

Figure 3 shows the blood pressures of the subjects grouped according to their blood glucose levels. Those with high blood glucose level in the hypertensive group had higher SBP than those with normal blood glucose level, especially in male subjects.

For the normotensive subjects, SBP values oscillated around $118 \mathrm{mmHg}$ for both males and females irrespective of their blood glucose grouping. DBP however was higher in those with high blood glucose level, irrespective of sex, and in both hypertensive and normotensive subjects.

Comparing the SBP values between the two blood glucose groups among the hypertensive subjects showed that the differences (within each sex) was significant $(\mathrm{p}<0.05)$. DBP gave similar results. The differences in the mean ages of hypertensive subjects with normal blood glucose concentrations and those with high blood glucose concentrations (within the sexes) showed no significance $(\mathrm{p}>0.05)$. The same was the case with the normotensives.

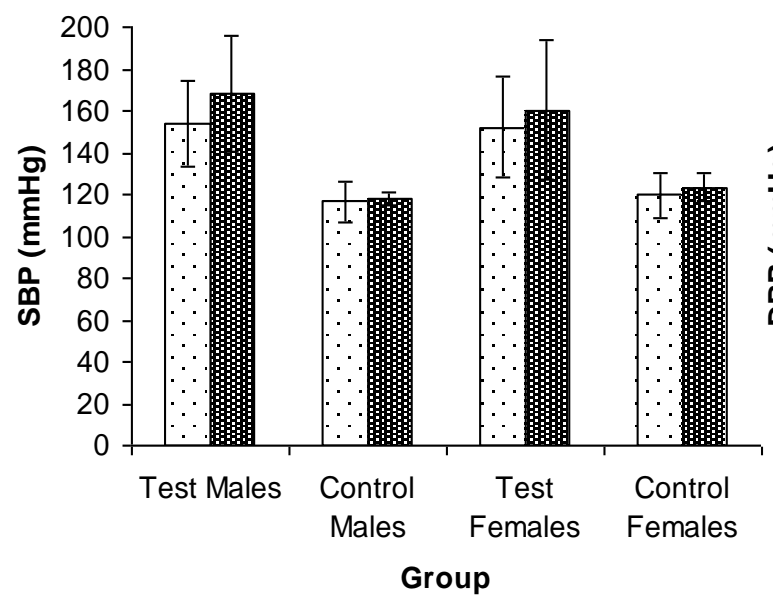

$\square$ Normal 㽗 High

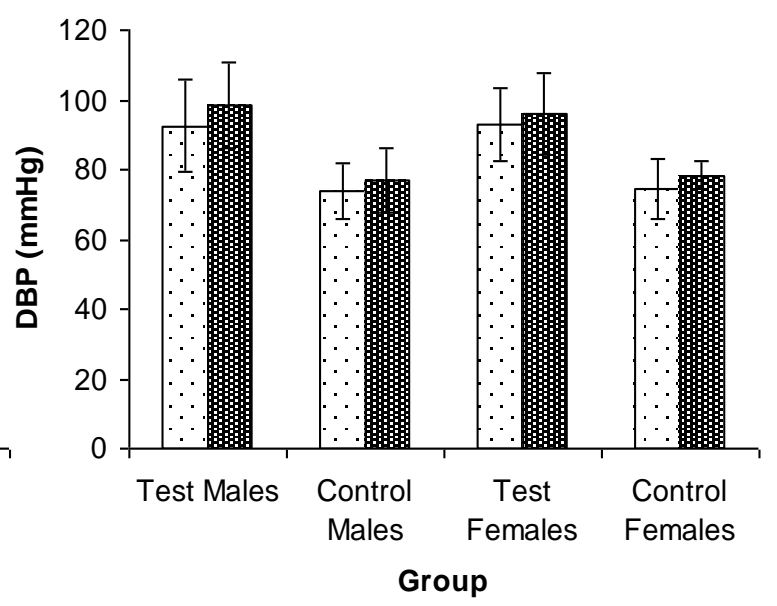

$\square$ Normal 略 High

Figure 3: Systolic and Diastolic blood pressures of subjects distributed according to their serum blood glucose concentrations

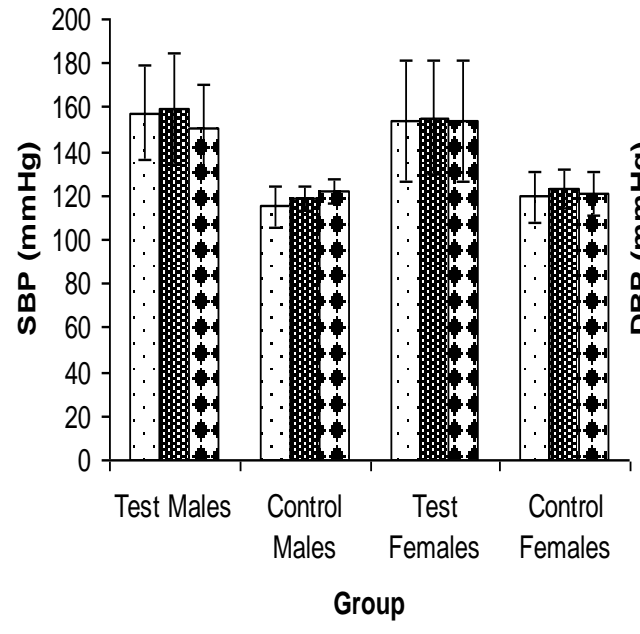

$\square$ Normal Overweight Obese

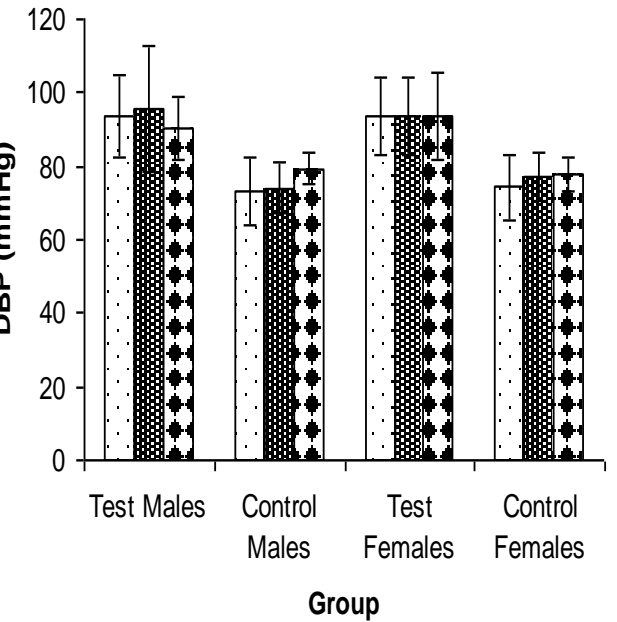

$\square$ Normal Overweight Obese

Figure 4: Systolic and Diastolic blood pressures of subjects distributed according to their BMI. 
Finally, classifying the subjects on the basis of their BMI showed that both SBP and DBP were higher in the higher BMI groups of the normotensives but not the hypertensives (Figure 4). In normotensive subjects, the changes in mean SBP and DBP for both males and females, with respect to the three BMI groups were not significant $(p>0.05)$. The same was the case in the hypertensive subjects, except for the differences between the mean DBP of overweight hypertensives compared to the obese ones, which was significant $(p<0.05)$. There was no significant $(p>0.05)$ difference in the mean ages of hypertensive subjects who had normal BMI and the others (within the sexes). The same trend was observed for the normotensive subjects.

\section{DISCUSSION}

Taken holistically, our data show that increases in age, serum total cholesterol level and blood glucose level resulted in increases in both systolic and diastolic blood pressures. The effects of age and blood glucose were weak $(r<0.2)$, while the effects of serum total cholesterol was stronger $(r>0.5)$. The regression analysis however show that only serum cholesterol contributed significantly to both SBP and DBP while age contributed significantly to only DBP. This disagrees with the findings of some researchers reporting an association between $\mathrm{BP}$ and $\mathrm{BMI}^{14,15,26}$, but agrees with others who reported associations between BP and serum total cholesterol, and $\operatorname{age}^{18-20}$.

Splitting the subjects up along lines of BP status gave clearer insights into the role of the studied variables in BP elevations. Among hypertensive subjects, both SBP and DBP increased marginally with age. While among normotensive subjects, SBP dropped from age 60-69, but DBP kept increasing with age, though slightly. Increase in BP was steeper in subjects with hypertension as against those with normal BP. Age apparently is a factor affecting blood pressure elevation. However other modifiable factors centering round nutrition and lifestyle, which may be exacerbated with age, may be more important than age as risk factors for $\mathrm{BP}^{27-30}$. Increase in age beyond 40-49 years, did not significantly increase BP in the population we studied. This disagrees with researchers who have reported an age-related increase in BP even beyond 50 years of age ${ }^{31,32}$. Other factors not assayed in this study may be responsible for this discrepancy.

Among subjects with high $\mathrm{BP}$, having undesirable cholesterol concentration significantly increased both systolic and diastolic blood pressures. But serum cholesterol concentration had little or no effect on the SBP and DBP of subjects with normal BP. The exact mechanisms, by which cholesterol results in elevated $\mathrm{BP}$, accelerate atherosclerosis and influence cardiovascular diseases are unclear. It has been suggested that cholesterol, particularly low density lipoprotein (LDL) cholesterol which accounts for about $60 \%$ of total cholesterol in circulation is taken up by macrophages. At high (undesirable) levels of cholesterol, macrophages take up more cholesterol than they can metabolize and then become 'foam cells'. These cells play important roles in atheromatous plaque formation and the subsequent narrowing of blood vessel walls $^{33,34}$. It appears serum cholesterol levels may be a risk factor for elevated BP only in subjects already hypertensive. The reason for this disproportionate response of BP to serum cholesterol levels is not clear to us.

Hypertensive subjects who had high blood glucose levels had higher SBP and DBP than those with normal blood glucose levels. The differences were wider in the male than in the female subjects. However, in subjects with normal BP, the differences in the SBP and DBP of the two blood glucose sub-sets were both negligible and insignificant. Sustained blood glucose elevation could lead to diabetes mellitus which often follows obesity (from imbalances in energy intake and expenditure) and may result in altered insulin response/sensitivity ${ }^{35}$. Insulin-resistant persons have reduced cholesterol absorption, but elevated endogenous synthesis ${ }^{36}$. This interrelationship may explain the atherogenic effects of glucose. It may also explain our observation that blood glucose levels affected $\mathrm{BP}$ in the same manner as serum total cholesterol, in this study.

$\mathrm{BMI}$ is widely said to correlate with $\mathrm{BP}^{14,15,26}$. Our study shows that among subjects with hypertension, SBP was lowest in the obese 
males while that of the females differed very negligibly with increasing BMI. The same trend was noticed for DBP. However, among the control subjects, BP increased with increasing BMI, though not significantly. Interpreting data on BMI is rather difficult. For most people, BMI provides a good measure of obesity, but does not provide actual information on body composition - the proportions of muscle, bone, fat and other tissues that make up a person's total body weight $^{37}$. Increasing weight has been shown to increase salt retention ${ }^{38}$, reduce physical activity $^{39}$ and lead to insulin resistance ${ }^{15}$. These are hypothesized to be the aspects of the major mechanisms by which increasing BMI influences BP. BMI may therefore be a proxy for other causal exposures. Our data shows that in the studied population, which is lean (average BMI 24.9), increasing BMI did not result in significant increases in BP. Other factors like genetics, diet, hormonal changes, physical activity, sodium metabolism, which the present study could not assess may be at play in the population. The regression models explained $55 \%$ of the studied variables $\left(\mathrm{R}^{2}=\right.$ 0.53 ) leaving an unexplained $45 \%$. It would appear from our data that BMI could be some cause of worry (from the point of high BP) only to those with normal blood pressures.

Blood pressure increased (though not significantly) with age in both hypertensive and normotensive subjects. Elevations in serum total cholesterol and blood glucose levels increased BP significantly only in hypertensive subjects. Increases in BMI however increased BP marginally in normotensive, but not hypertensive subjects. These results therefore support our hypothesis that risk factors for hypertension and cardiovascular diseases affect hypertensive and normotensive individuals disproportionately.

This study may be limited by sampling bias, as possibly those who knew they were hypertensive and were already managing it presented themselves for the study. This may explain the reason we had more hypertensive participants than normotensive ones. Our sample size is also not very large, warranting not just a careful interpretation of the data, but also testing the results in larger samples. BP values in our study may be lower than they would have been if we used mercury manometers. Automated devices tend to give lower BP values compared to mercury devices ${ }^{40}$. Nevertheless, the rigorous method we adopted for BP measurements per test subject make this study very informative of the population we studied. We have taken the investigation into the relationship between $\mathrm{BP}$ and some other cardiovascular risk factors and our results have important clinical and public health implications. We therefore suggest that the underlying mechanistic processes that link changes in these variables to their physiological consequences for BP elevation and regulation deserve more attention.

\section{REFERENCES}

1.Reddy, K. S. and Yusuf, S. (1998) Emerging epidemic of cardiovascular disease in developing countries. Circulation 97: 596-601

2.Davenport, R., Dennis, M., Wellwood, I. and Warlow, C. (1996) Complications after acute stroke. Stroke 27: 415-20.

3.MacMahon, S., Peto, R., Cutler, J., Collins. R., Sorlie, P., Neaton, J., Abbott, R., Godwin, J., Dyer, A. and Stamler, J. (1990) Blood pressure, stroke and coronary heart disease. Part 1: Prolonged differences in blood pressure: prospective observational studies corrected for the regression dilution bias. Lancet 335:765-774

4.Asia Pacific Cohort Studies Collaboration (APCSC) (2003) Blood pressure and cardiovascular disease in the Asia Pacific region. J. Hypertens. 21: 707-716

5.Klag, M., Whelton, P. K., Randall, B. L., Neaton, J. D., Brancati, F. L., Ford, C. E., Schulman, N. B. and Stamler, J. (1996) Blood pressure and end-stage renal disease in men. N. Engl. J. Med. 334:1318

6.Kannel, W. B. and Belanger, A. J. (1991) Epidemiology of heart failure. Am. Heart J. 138:205-210

7.Stokes, J. III, Kannel, W. B., Wolf, P. A., D'Agostino, R. B. and Cupples, L. A. (1989) Blood pressure as a risk factor for cardiovascular disease. The Framingham Study - 30 years of follow-up. Hypertension 13:113-118

8.Murray, C. J. L. and Lopez, A. D. (1996) Global health statistics. Global burden of 
disease and injury series. Harvard School of Public Health. Boston MA.

9.Pobee, J. O. M. (1990) Should hypertension control be considered a public health imperative in black Africa? J. Hum. Hypertens. 4:199

10.World Health Organization (2003) Diet, nutrition and the prevention of chronic diseases. Report of a joint WHO/FAO expert consultation. WHO Tech Rep Ser No 19 WHO Geneva

11.Bovet, P., Ross, A. G., Gervasoni, J., Mkamba, M., Mtasiwa, D. M., Lengeler, C., Whiting, D. and Paccaud, F. (2002) Distribution of blood pressure, body mass index and smoking habits in the urban population of Dar es Salam, Tanzania, and association with socioeconomic status. Int. J. Epidemiol. 31: 240-247

12.Stamler, R., Stamler, J., Riedlinger, W. F., Algera, C. T. and Roberts, R. H. (1978) Weight and blood pressure: findings in hypertension screening of 1 million Americans. JAMA 240:1607-1610

13.Cassano, P., Segal, M., Vokonas, P. and Weiss, S. T. (1990) Body fat distribution, blood pressure and hypertension: a prospective cohort study of men in the Normative Aging Study. Ann. Epidemiol. 1: $33-48$

14.Bunker, C. H., Ukoli, F. A., Mathews, K. A., Kriska, A. M., Huston, S. L. and Kuller, L. H. (1995) Weight threshold and blood pressure in a lean black population. Hypertension 26: 616-623

15.Kaufman, J. S., Asuzu, M. C., Mufunda, J., Forrester, T., Wilks, R., Luke, A., Long, A. E., Cooper, R. S. (1997) Relationship between blood pressure and body mass index in lean populations. Hypertension 30: 1511-1516

16.Gupter, R., Guptha, S., Gupta, V. P. and Prakash, H. (1995) Prevalence and determinants of hypertension in urban population of Jaipur in Western India. $J$ Hypertens 13: 1193-1200

17.Folson, A. R., Li, Y., Rao, X., Cen, R., Zhang, K., Liu, X. He, L., Irving, S., Dennis, B. H. (1994) Body mass, fat distribution, and cardiovascular risk factors in a lean population of South China. J. Clin. Epidemiol. 47: 173-181

18.Emberson, J. R., Whincup, P. H., Morris, R. W. and Walker, M. (2003) Re-assessing the contribution of serum total cholesterol, blood pressure and cigarette smoking to the aetiology of coronary heart disease: impact of regression dilution bias. Eur. Heart J. 24: 1719-1726

19.Iribarren, C., Sharp, D., Burchfiel, C. M., Sun, P. and Dwyer, J. H. (1996) Association of serum total cholesterol with coronary disease and all-cause mortality: multivariate correction for bias due to measurement error. Am. J. Epidemiol. 143: 467-471

20.Kemp, T. M., Barr, E. L. M., Zimmet, P. Z., Cameron, A. J., Welborn, T. A., Colagiuri, S., Phillips, P. and Shaw, J. E. (2005) Glucose, lipid and blood pressure control in Australian adults with type 2 diabetes. Diabetes care 28: 14901492

21.Guidelines Subcommittee (1999) World Health Organizaion International Society of Hypertension guidelines for the management of hypertension. $J$. Hypertens. 17:151-183

22.World Health Organizaion (1995) Physical status: the use and interpretation of anthropometry. Report of a WHO expert committee. WHO Tech Rep Ser 854: $1-452$

23.NIH/NHLBI (National Institutes of Health, National Heart Lung and Blood Institute) (1998) Clinical guidelines on the identification, evaluation and treatment of overweight and obesity in adults. US Department of Health and Human Services, Public Health Series

24.Allain, C. C., Poon, L. S., Chan, C. S. C., Richmond, W. and Fu, P. C. (1974) Enzymatic colorimetric method for cholesterol estimation. Clin. Chim. 20:470-475

25.Kratz, A., Ferraro, M., Sluss, P. M. and Lewandrowski, M. D. (2004) Laboratory reference values. N. Engl. J. Med. 351: $1548-1563$

26.Jones, D. W., Kim, J. S., Andrew, M. E., Kim, S. J. and Hong, Y. P. (1994) Body mass index and blood pressure in Korean men and women: the Korean National Blood Pressure Survey. J. Hypertens. 12: 1433-1437

27.Poulter, N. R., Khaw, K. T., Mugambi, M., Peart, W. S., Rose, G. and Sever, P. (1985) Blood pressure patterns in relation to age, weight and urinary electrolytes in 
three Kenyan communities. Trans. R. Soc. Trop. Med. Hyg. 79: 389-392

28.Kaufman, J. S., Owoaje, E. E., James, S. A., Rotimi, C. N. and Cooper, R. S. (1996) Determinants of hypertension in West Africa: Contribution of anthropometric parameters to urban-rural and socioeconomic gradients. Am. J. Epidemiol. 143: 1203-1218

29.Colhoun, H., Herningway, H. and Poulter, N. R. (1998) Socioeconomic status and blood pressure: an overview analysis. J. Hum. Hypertens. 12:91-110

30.Mendez, M. A., Cooper, R., Wilks, R. and Forrester, T. (2005) Income education and blood pressure in adults in Jamaica, a middle-income developing country. Int. J. Epidemiol. 32: 400-408

31.Singh, R. B., Rastogi, S. S., Rastogi, V., Niaz, M. A., Madhu, S. V., Chen, M., Shoumin, Z. (1997) Blood pressure trends, plasma insulin levels and risk factors in rural and urban elderly populations of north India. Coron. Artery Dis. 8: 463-468

32.Tesfaye, F., Nawi, N. G., Minh, van H., Byass, P., Berhane, Y., Bonita, R. and Wall, S. (2007) Association between body mass index and blood pressure across three populations in Africa and Asia. $J$. Hum. Hypertens. 21:28-37

33.Bronner, L. L., Kanter, D. S. and Manson, J. E. (1995) Primary prevention of stroke. N. Engl. J. Med. 333:1392-1400

34.Gorelick, P. B., Schneck, M., Berglund, L. F., Feinberg, W., Goldstone, J. (1997)
Status of lipids as a risk factor for stroke. Neuroepidemiology 16: 107-115

35.Reaven, G. M., Lithell, A. and Landsberg, L. (1996) Hypertension and associated metabolic abnormalities: the role of insulin resistance and sympathetic adrenal system. N. Engl. J. Med. 334: 374381

36.Pihlajamaki, J., Gylling, H., Miettinen, T. A. and Laakso, M. (2003) Insulin resistance is associated with increased cholesterol synthesis and decreased cholesterol absorption in normoglycaemic men. J. Lipid Res. 45: 507-517

37.Hiza, H. A., Pratt, C., Mardis, A. L. and Annand, R. (2000) Body mass index and health. USDA Center for Nutrition Policy and Promotion Nutrition Insights, Insight 16

38.Rocchini, A. P., Key, J., Bondie, D., Chico, R., Moorehead, C., Katch, V. and Martin, M. (1989) The effect of weight loss on the sensitivity of blood pressure to sodium on obese adolescents. N. Engl. J. Med. 321: 580-585

39.Nelson, L., Jennings, G. L., Esler, M. D. and Korner, P. I. (1986) Effect of changing levels of physical activity on blood pressure and haemodynamics in essential hypertension. Lancet 2: 473-76

40.Lithell, H. and Berglund, L. (1998) Validation of an oscillometric blood pressure monitoring device: a sub-study of the HOT study (Hypertension Optimal Treatment). Blood Pressure 7: 149-152 